\title{
Polymer Network Gel Method for Surperfine AIN Powder Preparation
}

\author{
Liuyan Wang ${ }^{1, a}$ \\ ${ }^{1}$ College of architecture and civil engineering, Shenyang University, Shenyang 110000, China
}

\begin{abstract}
To research mixing uniformity of precursor was helpful to improve the quality of the powder late processing. Layered problems of the precursor comprised of aluminium source and of carbon source were well solved by the polymer network method. High quality raw precursor was synthesized by new process which contained polyacrylamide-gel method and carbothermal process. The synthesized precursor was investigated to obtain porous structure precursor. The results showed that sucrose was more suitable for the preparation of AlN precursor. The effect of reaction temperature and heating time on the phase composition of AlN powder were also studied. In this work, ultrafine nano-sized AIN powder was prepared at low temperature.
\end{abstract}

\section{Introduction}

There are many scholars devoted to the low temperature preparation of density AlN ceramic, in order to exert its features such as high thermal conductivity, good electrical resistivity, high melting temperature, good thermal shock resistance, wide band gap, low dielectric constant and high mechanical strength, etc, which may be useful for high integration of semiconductor substrate and electronics packaging applications. High quality raw material (AIN precursor) is believed to be one of the ways to achieve this purpose. For this, we improved the traditional preparation technology, and studied the effect of improvement process on the preparation of ultrafine aluminium nitride.

At present, it was shown that cabothermal reduction method [1-5], high energy ball-milling method [6,7], mechanical activated method [8,9], sol-gel technique [10-13], direct-nitridation[14,15] and chemical vapour deposition[16-19], were widely used for the preparation of AlN. However, these synthesis processes suffering from various problems, including inferior crystal structure, non-uniform microstructure and complex process as well as high cost of raw material. So improving the uniformity of precursor, technological process and recovery rate become the key technologies which need to resolve during the preparation of AlN powder.

In this work, $\mathrm{C}_{3} \mathrm{H}_{5} \mathrm{NO}$ was used as monomer. $\mathrm{C}_{7} \mathrm{H}_{10} \mathrm{~N}_{2} \mathrm{O}_{2}$ was used as crosslinking network. $\left(\mathrm{NH}_{4}\right)_{2} \mathrm{~S}_{2} \mathrm{O}_{8}$ was used as initiator. And $\mathrm{Al}\left(\mathrm{NO}_{3}\right)_{3} \cdot 9 \mathrm{H}_{2} \mathrm{O}$ was used as Alumium source for its lower prices. The precursor was prepared by polyacrylamide gel method, which was best solved the layered phenomenon of $\mathrm{Al}$ and $\mathrm{C}$ source. The polymer gel network was produced by functional groups activation of the double bond using acrylamide as monomer. The activity of ion was reduced by the effect of gel network blocking. And the reunion opportunity in the process of precipitation and

\footnotetext{
${ }^{\text {a }}$ Corresponding author:w.ly428@163.com
} 
sintering was also decreased. These results would lay the foundation for the further studies on the ultrafine of AlN powder.

\section{Experimental}

\subsection{Technological process of AIN precursor}

A certain amount of monomer, network agent and initiator (weight ratio of 5:1:1) was added into 0.3 $\mathrm{mol} / \mathrm{l}$ of aluminum nitrate solution, and was magnetically stirred for $30 \mathrm{~min}$. The temperature in this titration process was controlled below $0^{\circ} \mathrm{C}$. Meanwhile, carbon sources (sucrose or active carbon) were prepared. Here the molar ratio of $\mathrm{C}$ and $\mathrm{Al}$ was $6: 1$. After $3.42 \mathrm{~g}$ of sucrose was added into the mixture and stirring for $60 \mathrm{~min}$. Then ammonia solution was dripped into the mixtures with the concentration ratio of $1: 2$ and $3-5 \mathrm{ml} / \mathrm{min}$ dripping speed. When titration was finished, the reaction mixture was continued to stir for $120 \mathrm{~min}$. The prepared wet gel was obtained until the mixture was aggregated at $65^{\circ} \mathrm{C}$ for $120 \mathrm{~min}$. Final AIN precursor was obtained while the wet-gel directly drying at $85^{\circ} \mathrm{C}$ for $120 \mathrm{~min}$ in the vacuum drying oven.

All raw materials $\left(\mathrm{Al}\left(\mathrm{NO}_{3}\right)_{3} \cdot 9 \mathrm{H}_{2} \mathrm{O}, \mathrm{NH}_{3} \cdot \mathrm{H}_{2} \mathrm{O}, \mathrm{C}_{12} \mathrm{H}_{22} \mathrm{O}_{11}, \mathrm{C}_{3} \mathrm{H}_{5} \mathrm{NO}, \mathrm{C}_{7} \mathrm{H}_{10} \mathrm{~N}_{2} \mathrm{O}_{2}\right.$ and $\left(\mathrm{NH}_{4}\right)$ ${ }_{2} \mathrm{~S}_{2} \mathrm{O}_{8}$ ) used in the preparation of AlN precursor were $99 \%$ in purity.

The synthesis of nanosized AIN powder was carried out in vacuum carbothermal reducing furnace. The AlN precursor was heated in a flowing nitrogen gas at various temperatures in the range of 1100$1500^{\circ} \mathrm{C}$ for $120 \mathrm{~min}$. And the flow rate of nitrogen was $10 \mathrm{l} / \mathrm{min}$. Residual carbon in each nitridation product was removed by firing in air at $640^{\circ} \mathrm{C}$ for $240 \mathrm{~min}[20]$.

\subsection{Characterization}

Phase analysis of the nitridation reaction products for AlN precursor calcined at different temperature were carried out by X-ray diffraction (XRD, PhilipPw3040/60) using monochromatic $\mathrm{Cu}$ K $\alpha$ radiation with the X-ray wavelength of $0.154 \mathrm{~nm}$, operated at $20 \mathrm{kV}$.

Microstructures of the reaction products were observed using field emission scanning electron microscopy (SEM, SSX-550, Shimadzu Corporation). Element distributions of sample were analyzed by energy dispersive X-ray spectroscopy (EDS). Here EDS was used to assist the SEM analysis.

\section{Results and Discussion}

\subsection{Effect of different carbon sources on the precursor}

AlN precursors were synthesized by means of polyacrylamide gel method with ammonia as precipitant, sucrose and activated carbon as carbon source, respectively. Here the molar ratio of $\mathrm{C}$ to Al was 2:1.The SEM images of AlN precursor synthesized by different carbon source were shown in Fig.1. It was evident that the section of AlN precursor which used activated carbon as carbon source presents obvious layers. However, AlN precursor with sucrose that contains a homogeneous mixture of very fine alumina and carbon particle can be obtained in this work. Compared with active carbon, sucrose was more suitable for well-proportioned precursor. Sucrose was used as carbon source based on the above reason. 


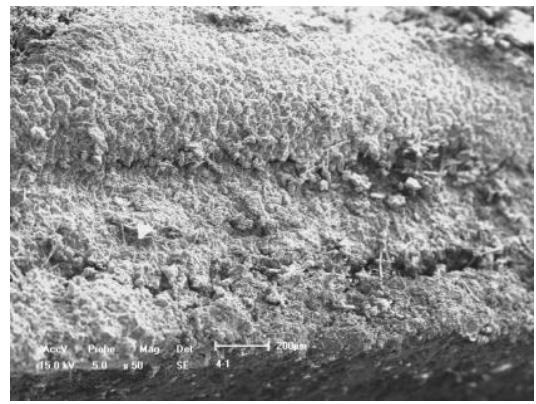

(a)

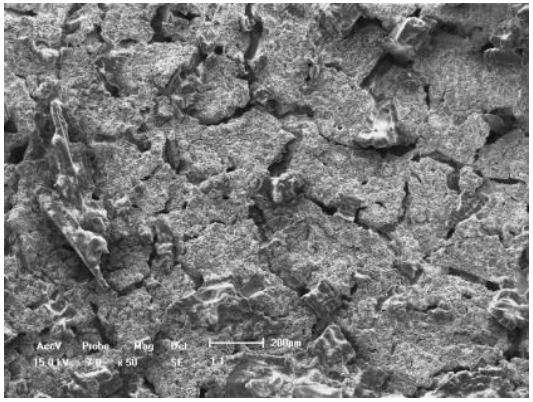

(b)

Figure 1. SEM images of AIN precursor prepared by ammonium hydroxide with different carbon source (a) sucrose (b) activated carbon

\subsection{Effect of sucrose on the uniform precursor}

The SEM images of AlN precursor under different magnification were shown in Fig.2. The sample was observed under low magnification. And there was no obvious stratification in it (see Fig.2(a).

To further study the microstructure and distribution of precursor sample, it was magnified 2000 times by SEM, as shown in Fig.2(b). Meanwhile, the microstructure of the precursor was porous structure. It would suggest that adding liquid sucrose may accelerate the formation of network structure. The elementary and crosslinking reaction of polymeric hydrogel and small molecule of liquid sucrose can explain this phenomenon very well.

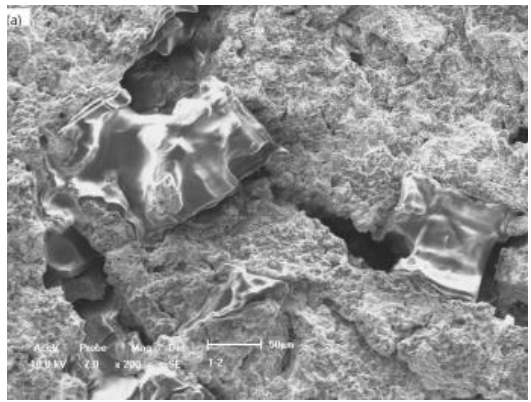

(a)

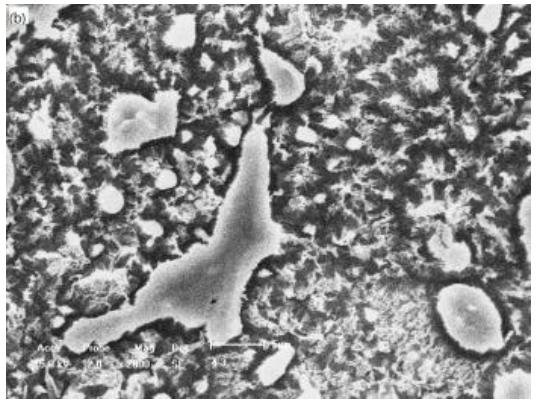

(b)

Figure 2. SEM images of AlN precursor under different magnification (a) 200times magnification (b) 2000times magnification

Fig. 3 shows surface scanning images of AlN precursor using ammonium hydroxide and sucrose as raw material. Fig.3a shows that AIN gel precursor has crosslinked and the network structure formed. As shown in Fig. $3 \mathrm{~b}, \mathrm{c}$ and d, elements composition and distribution in AlN precursor were also studied by lateral scanning. Fig.3b, c and d show the distribution of $\mathrm{Al}, \mathrm{C}$ and $\mathrm{O}$ atoms in aluminum nitride precursor, respectively. Continuous and uniform distribution of $\mathrm{C}$ atoms in AlN precursor was clearly seen from Fig.3c.
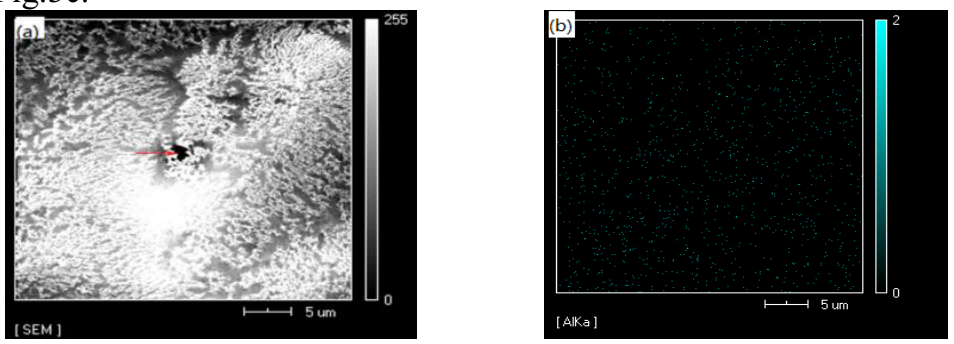

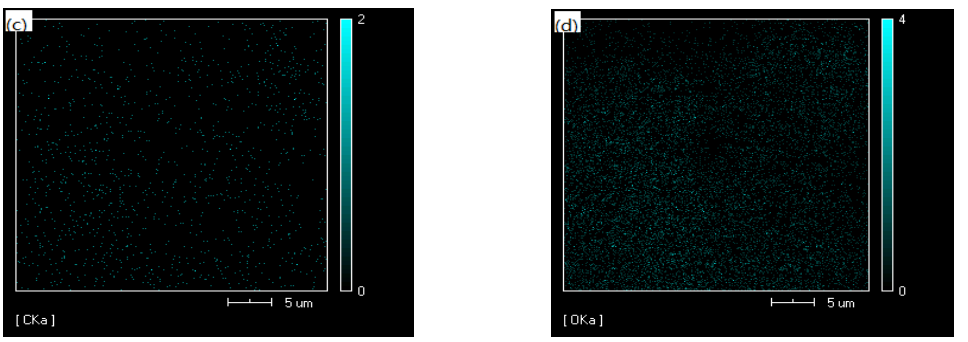

Figure 3. Surface scanning images of AlN precursor

\subsection{Effect of reaction temperature on the phase composition of AIN powder}

So far, detailed reaction mechanism for the synthesis of AlN powder by carbon thermal reduction method was unclear. Based on some research [21], the nitridation reaction of AlN powders prepared by carbon thermal reduction may be suggested as the following equation:

$$
\mathrm{Al}_{2} \mathrm{O}_{3(s)}+3 \mathrm{C}_{(s)}+\mathrm{N}_{2(g)} \rightarrow 2 \mathrm{AlN}_{(s)}+3 \mathrm{CO}_{(g)}
$$

The Gibbs free-energy values for reaction were calculated to confirm a driving force. According to some theories in some paper [22], the initial reaction temperature is $1400^{\circ} \mathrm{C}$. A series of AlN powders were prepared at various temperatures by the carbothermal reduction method using AIN precursor as raw material.

Fig. 4 shows the reaction products of AIN precursor under various temperatures. The XRD patterns of AlN precursor and products that were calcined at different temperature for $2 \mathrm{~h}$ were shown in Fig. 4.

From Fig.4a, the XRD pattern of the sample obtained at $1400^{\circ} \mathrm{C}$ showed that AlN phase was formed together with the diffraction peaks of $\mathrm{Al}_{2} \mathrm{O}_{3}$ and $\mathrm{C}$. This suggests that the $\mathrm{AlN}$ precursor was not completely sintered.

Compared with JCPDS Card No.25-1133, some diffraction peaks represent the existence of AlN. Fig. $4 \mathrm{~b}$ shows that the intensities of AlN peaks increased when the temperature was up to $1450^{\circ} \mathrm{C}$. The diffraction peaks of $\mathrm{Al}_{2} \mathrm{O}_{3}$ was still detected in the sample, as Fig. $4 \mathrm{~b}$ shown.

However, when the sample was obtained at $1500^{\circ} \mathrm{C}$, only $\mathrm{AlN}$ and small amounts of $\mathrm{C}$ were present without any other detectable peaks (see Fig.4c). The presence of excess carbon in the reaction product possibly prevented the growth of AlN particle [23].

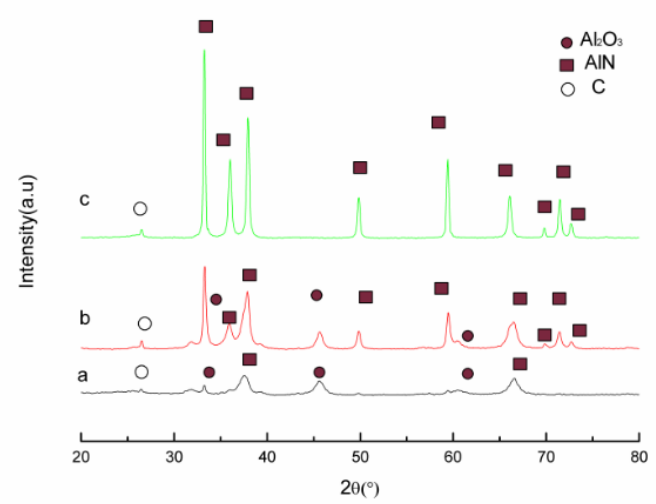

Figure 4. XRD patterns of reaction products obtained at different temperature for $2 \mathrm{~h}$. 


\subsection{The superfine AIN powder}

AlN powder was prepared by carbon thermal reduction method sintering $1500^{\circ} \mathrm{C}$ for $2 \mathrm{~h}$ using AlN precursor as raw material. The superfine AlN powder can be obtained by reaction product sintering at $650^{\circ} \mathrm{C}$ for $4 \mathrm{~h}$ to remove excess carbon.Fig. 5 shows the SEM image of AlN powder synthesized at $1500^{\circ} \mathrm{C}$ for $2 \mathrm{~h}$. No abnormal large particle can be observed and the average particle size was likely to be $40-80 \mathrm{~nm}$. Since the presence of excess carbon in the mixture possibly inhibited the growth of AlN grain [23], the particles of synthesized AlN powder observed in Fig. 6 are very fine.

The XRD patterns of the final AIN powders are shown in Fig. 5, the main peaks can well correspond to the characteristic peaks of hexagonal AIN. It can be seen clearly that single AlN phase was found in the synthesis powder calcined at $1500^{\circ} \mathrm{C}$ heated for $2 \mathrm{~h}$. It can be seen clearly that single AlN phase was found in the synthesis powder calcined at 1500 heated for $2 \mathrm{~h}$. Compared with the sintering temperature of conventional synthesis method, the powder prepared by this process was purity and the sintering temperature was lower.

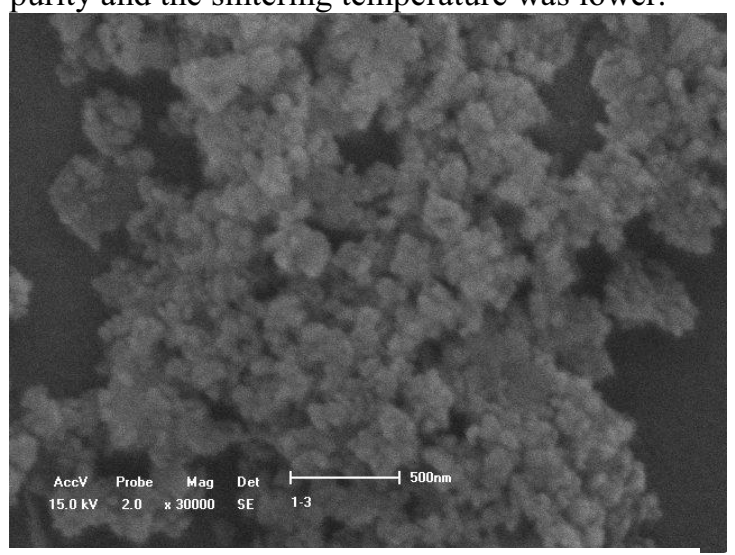

Figure 5. SEM image and XRD pattern of AIN powder synthesized at $1500^{\circ} \mathrm{C}$ for $2 \mathrm{~h}$

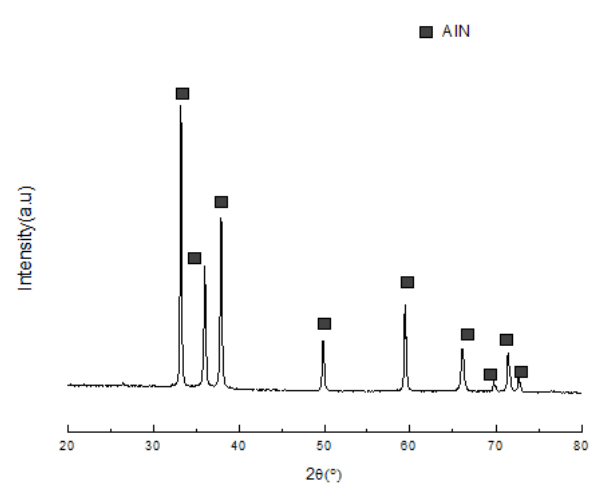

Figure 6. XRD pattern of AlN powder synthesized at $1500^{\circ} \mathrm{C}$ for $2 \mathrm{~h}$

\section{Conclusions}

In this paper, aluminum and carbon source were homogeneously distributed in the AlN precursor with sucrose. Optimum process for AlN powder which prepared by carbon thermal reduction method was $1500^{\circ} \mathrm{C}$ for $2 \mathrm{~h}$ followed by heating at $650^{\circ} \mathrm{C}$ for $4 \mathrm{~h}$ to remove any extra carbon. The superfine AlN powder with smaller size was successfully synthesized by using above process. Meanwhile, this synthesis process is superior to the traditional preparation process with single aluminum and carbon source. It can lower the reaction temperature and reduce heating time for conversion of AIN precursor. And the process in this paper could be suitable to the preparation of high density ceramics.

\section{References}

1. Hashimoto N, Sawada Y, Bando T, et al. Preparation of Aluminum Nitride Powder from Aluminum Polynuclear Complexes [J]. Journal of the American Ceramic Society, 1991, 74(6):1282-1286.

2. Tsuge A;Inoue $\mathrm{H}$; Kasori $\mathrm{M}$, et al. Raw material effect on $\mathrm{AIN}$ powder synthesis from $\mathrm{Al} 2 \mathrm{O} 3$ carbothermal reduction. Journal of Materials Science. 1990, 25, 2359-2361.

3. Qin M L, Du X L, Li S, et al. Preparation of AlN powders from precipitated precursor [J]. Chinese Journal of Nonferrous Metals, 2005.

4. Dai C, Zhang X, Liu S. Study of Mechanism for Microwave Synthesis of Ultrafine AIN Powder [J]. Journal of Inorganic Materials, 1997, 12(5):755-758. 
5. Komeya K; Mitsuhashi E; Meguro T. Synthesis of AIN Powder by Carbothermal ReductionNitridation Method: Effect of Additives on Reaction Rate [J]. Journal of the Ceramic Society of Japan. 1993, 101:377-382.

6. G. B. Schaffer; P. G. Mc Cormic. Reduction of oxides by mechanical alloying. Appl Phys Lett.1989, 55, 45-46.

7. Calka A; Nikolov J I;Wantenaar G H J. Low temperature synthesis of Al-AlN composites from a nanostructure made by controlled magneto-ball milling of Al in ammonia. Journal of Applied Physics, 1994, 75, 4953-4955.

8. Peng-Liang L I, Zhou J E, Sheng-Qi X I. Cubic AlN Synthesized by High Energy Ball Milling and Its Phase Conversion at High Temperature [J]. Journal of Inorganic Materials, 2006, 21(4):821-827.

9. Liu X, Ma M, Xi S. Study on mechanical activation synthesis of nano-crystal aluminium nitride [J]. Journal of the Chinese Ceramic Society, 2000.

10. Yan-Hong M A, Chen W. Preparation of AlN by the Sol-Gel Method [J]. Vacuum Electronics, 2009.

11. Xue li D U, Qin M L, Sun W, et al. Preparation and Sintering of Nanometer AlN Powders[J]. Vacuum Electronics, 2006.M.L.Qin; X.H.Qu; J.L.Lin. synthesis of ultrafine aluminium nitride powder by sol-gel process. Mater Sci Eng powder Metal.2002, 7, 51- 53.

12. Baraton M I, Chen X, Gonsalves K E. FT-IR surface characterization of a nanostructured aluminum nitride powder prepared via sol-gel chemical synthesis [J]. 1995.

13. Nur Fahana M A; Lee Z Y; Fong C Y, et al. Growth and Characterization of Aln Thin Film Deposited by Sol-Gel Spin Coating Techniques. Advanced Materials Research.2015, 1107:667671.

14. Kimura I; Ichiya K; Ishii M, et al. Synthesis of fine AlN powder by a floating nitridation technique using an N2/NH3 gas mixture. Journal of Materials Science Letters.1989, 8,303-304.

15. Hwang $C \mathrm{C}$, Lin $\mathrm{C} \mathrm{S}$, Wang G P, et al. A self-propagating high-temperature synthesis method for synthesis of zinc oxide powder. Journal of Alloys \& Compounds, 2009, 467(1-2):514-523.

16. Y.M.Zhao; G.S.Sun; J.Y, .Lee,etal. Growth of a Novel Periodic Structure of SiC/AlN Multilayers by Low Pressure Chemical Vapour DepositionGrowth of a Novel Periodic Structure of SiC/AIN Multilayers by Low Pressure Chemical Vapour DepositionChinese Physics Letters.2007, 24, 1753-1755.

17. Dollet A, Casaux Y, Chaix G, et al. Chemical vapour deposition of polycrystalline AlN films from $\mathrm{AlCl} 3-\mathrm{NH} 3$, mixtures. : Analysis and modelling of transport phenomena [J]. Thin Solid Films, 2002, 406(1-2):1-16.

18. Sun Y; Zhu R; Ye H, et al. Towards a bioinformatics analysis of anti-Alzheimer's herbal medicines from a target network perspective. Briefings in Bioinformatics, 2013, 14,327-343.

19. Cimalla V, Foerster C, Cengher D, et al. Growth of AlN nanowires by metal organic chemical vapour deposition. Physica Status Solidi, 2006, 243, 1476-1480.

20. Zhang D. Synthesis of AlN Powders by Carbonthermal Reduction Method [J]. Non-metallic Mines, 2001.

21. Wang J;Wang W L; Ding P D, et al. Synthesis of cubic aluminum nitride by carbothermal nitridation reaction. Diamond \& Related Materials, 1999, 8, 1342-1344.

22. Pankratz, L. B., Stuve, J. M., Gokcen, N. A., \& Mines., U. S. B. O. (1984). Thermodynamic data for mineral technology.

23. L.C. Pathak; A. K.Ray;S.Das; C.S.Sivaramakrishnan, P.Ramachandrarao,J.Am.Ceram.Soc. 1999, $82,257-260$. 